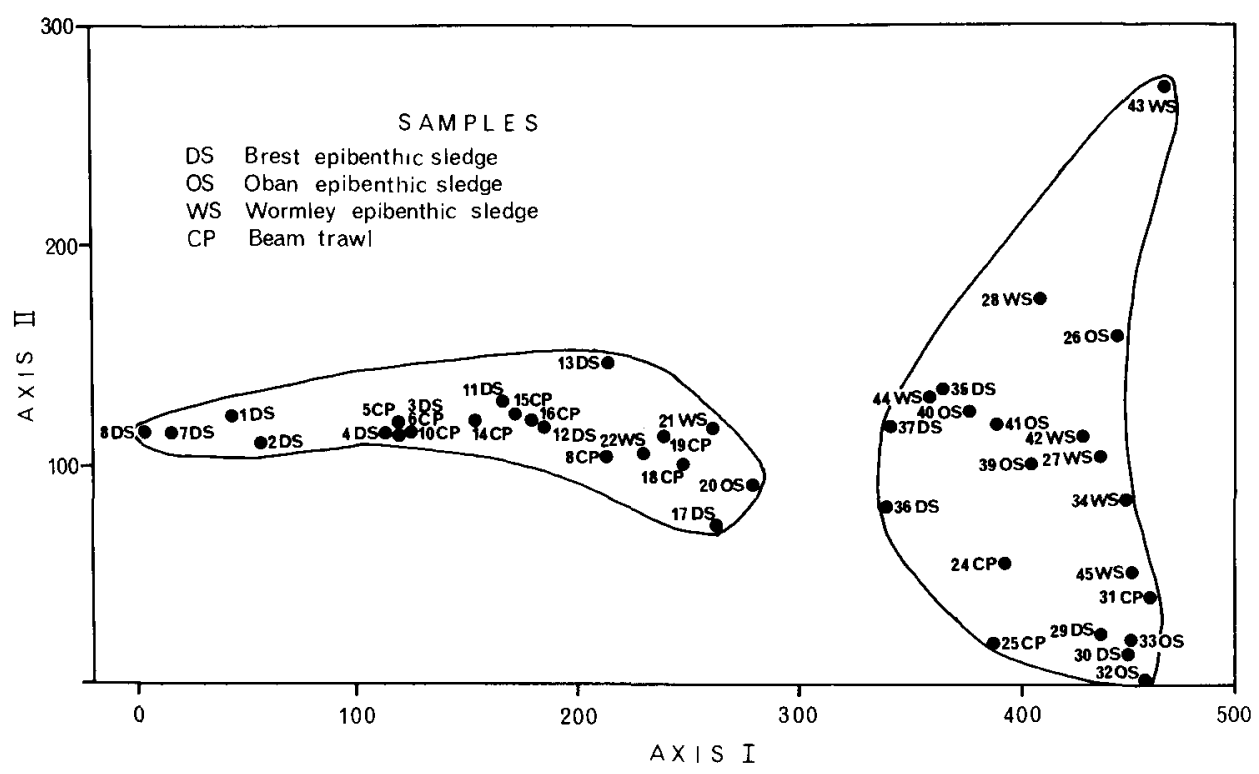

Figure 1. First axis ordination by detrended correspondence analysis of the INCAL Cruise samples.

No significant differences were apparent between the different types of collecting gear for the numbers of species or specimens of cumaceans collected in the southern area where each type of gear was used. The samples were sorted by the Centre National de Tri d'Océanographie Biologique.

\title{
A spider crab and its larvae
}

\section{I. Williamson}

Department of Marine Biology, University of Liverpool, Port Erin, Isle of Man

Dorhynchus thomsoni Thomson is a small spider-crab (Brachyura, superfamily Majoidea), common on the slopes of the Rockall Trough. The adult resembles Inachus, Macropodia and Achaeus, (Majoidea, family Inachidae), but the larvae are unique.

Most zoeas of brachyuran crabs have four carapace spines, but examples with fewer spines are not uncommon, and Inachus, Macropodia and Achaeus have only one. Zoeas with more than four carapace spines are very rare, but Dorhynchus has fourteen spines and two blunt processes (Fig. 1). Its telson and appendages resemble those of other Inachidae, although some of the spines are unusually large.

The only other known larvae with a similar pattern of spines are late zoeas of Homola (Brachyura, superfamily Homoloidea), a very primitive crab with no close affinities with the Inachidae. Perhaps Homola has retained the ancestral form of 


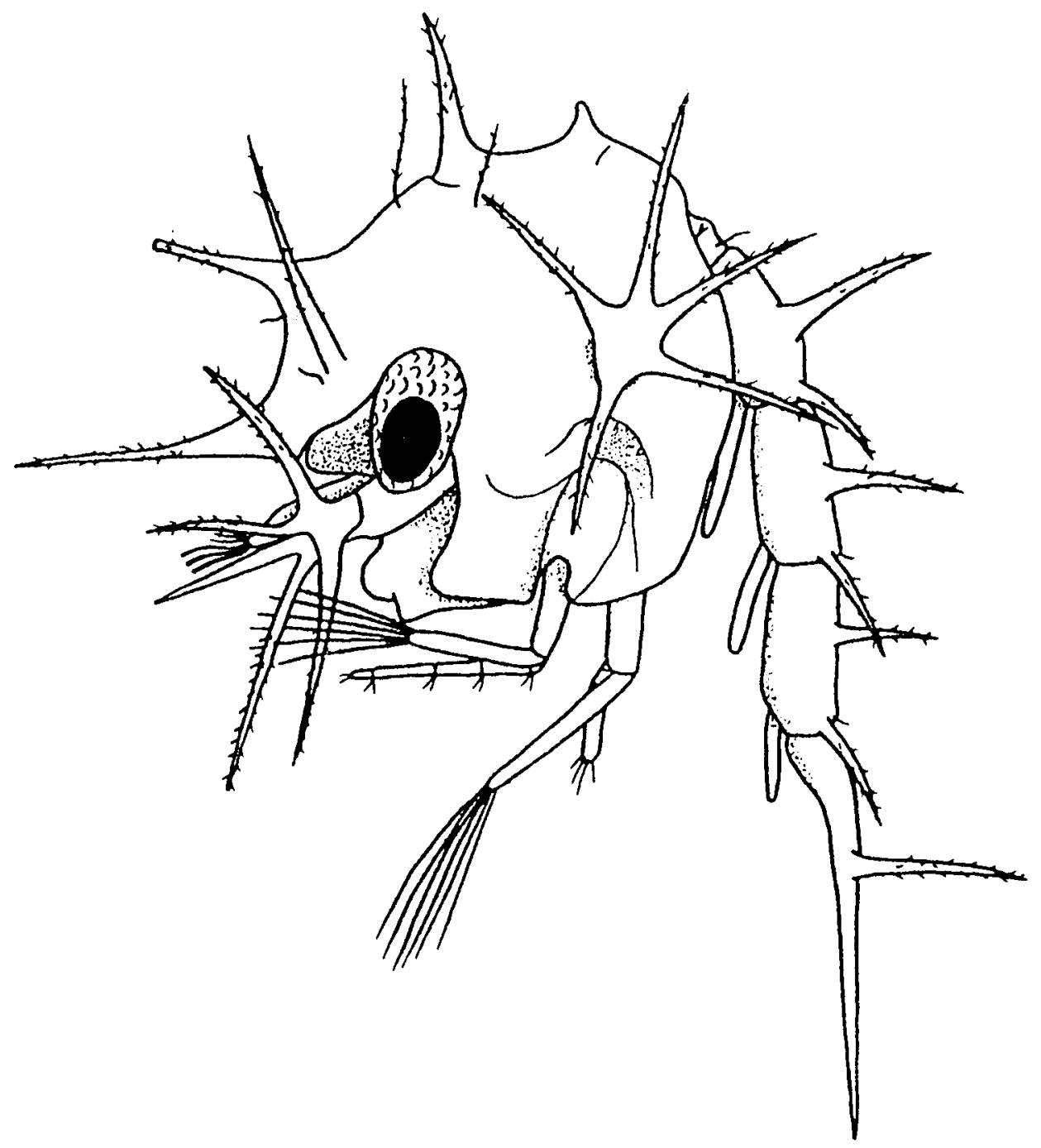

Figure 1. Dorhynchus thomsoni Thomson. Zoea II.

brachyuran zoeal carapace. Most crabs might have retained the corresponding genes in a suppressed state, and these genes might have become re-activated in Dorhynchus. There are no suggestions as to what might have brought about this postulated re-activation. An alternative suggested explanation involves the transfer of genetic material between animals which are not closely related. 